\title{
Interannual changes in the overflow from the Nordic Seas into the Atlantic Ocean through Denmark Strait
}

\author{
A. Macrander, ${ }^{1}$ U. Send, ${ }^{2,3}$ H. Valdimarsson, ${ }^{4}$ S. Jónsson, ${ }^{5,6}$ and R. H. Käse ${ }^{7,8}$ \\ Received 9 April 2004; revised 3 November 2004; accepted 5 January 2005; published 24 March 2005.
}

[1] The global thermohaline circulation is an important part of Earth's climate system. Cold, dense water formed in the Nordic Seas enters the Atlantic Ocean as overflows across the sills of the Greenland-Scotland Ridge. The Denmark Strait Overflow (DSO) is one of the main sources of North Atlantic Deep Water. Until now the DSO has been believed to be stable on interannual timescales. Here, for the first time, evidence is presented from a 4-year program of observations showing that overflow transports in 1999/ 2000 were approximately 30\% higher than previous estimates. Later, transports decreased remarkably during the observation period, coincident with a temporary temperature increase of about $0.5^{\circ} \mathrm{C}$. Citation: Macrander, A., U. Send, H. Valdimarsson, S. Jónsson, and R. H. Käse (2005), Interannual changes in the overflow from the Nordic Seas into the Atlantic Ocean through Denmark Strait, Geophys. Res. Lett., 32, L06606, doi:10.1029/2004GL021463.

\section{Introduction}

[2] Dense water formed in the Nordic Seas passes across the $600 \mathrm{~m}$ deep Denmark Strait sill between Greenland and Iceland (Figure 1a), before it descends and joins the southward moving deep branch of the global overturning circulation [Talley, 1996; Hansen and Østerhus, 2000; Saunders, 2001]. Previous observations of the Denmark Strait overflow indicated a rather stable volume transport of about 2.7-2.9 Sv $\left(1 \mathrm{~Sv}=10^{6} \mathrm{~m}^{3} \mathrm{~s}^{-1}\right)$ on timescales longer than weeks [Aagaard and Malmberg, 1978; Dickson and Brown, 1994].

[3] However, an unchanging overflow is difficult to rationalize, since the DSO is fed by intermediate and deep waters of the Nordic Seas, where interannual variability of production rates and water mass properties have been observed (J. Karstensen et al., Variability of water mass formation in the Greenland Sea during the 1990s, submitted to Journal of Geophysical Research, 2004). Since the overflow seems to

\footnotetext{
${ }^{1}$ Leibniz-Institut für Meereswissenschaften, IFM-GEOMAR, Kiel, Germany.

${ }^{2}$ Leibniz-Institut für Meereswissenschaften, IFM-GEOMAR, Kiel, Germany.

${ }^{3}$ Now at Scripps Institution of Oceanography, La Jolla, California, USA.

${ }^{4}$ Marine Research Institute, Reykjavík, Iceland.

${ }^{5}$ Department of Natural Resource Sciences, University of Akureyri, Akureyri, Iceland.

${ }^{6}$ Also at Marine Research Institute, Reykjavík, Iceland.

${ }^{7}$ Zentrum für Meeres- und Klimaforschung, Institut für Meereskunde, Hamburg, Germany.

${ }^{8}$ Also at Leibniz-Institut für Meereswissenschaften, IFM-GEOMAR, Kiel, Germany.
}

Copyright 2005 by the American Geophysical Union. 0094-8276/05/2004GL021463\$05.00 be governed by hydraulic control to some extent (see Figure 1b) [Whitehead, 1998], density and upstream reservoir height changes should have an effect on the DSO.

[4] The overflow measurements available so far were either short-term experiments [Worthington, 1969; Ross, 1984; Girton, 2001], with low spatial resolution [Aagaard and Malmberg, 1978], or were obtained far downstream [Dickson and Brown, 1994], where the overflow is already significantly changed due to entrainment processes (Figure 1b). At the sill, no continuous time series exists that allow for consistent estimates of the interannual variability of the original dense water export from the Nordic Seas through Denmark Strait. Therefore, a program was started in 1999 in the framework of the SFB460 project at the University of Kiel to obtain long-term observations of the overflow at its very source. The measurements were conducted in cooperation with the Marine Research Institute in Iceland.

[5] Transport observations directly at the sill are preferable in some respects, since there the original transport can be observed prior to modifications by entrainment or other downstream processes (Figure 1b). Only there, hydraulic concepts can be tested and related to the transports to improve the understanding of the mechanisms that control the overflow. Also, the part of the section that can be occupied by dense overflow water (deeper than $300 \mathrm{~m}$ ) is only approx. $100 \mathrm{~km}$ wide (Figure 1a) so that a small number of deployments may suffice to capture the transport. Disadvantages are heavy fishing activities that allow only trawl-resistant bottom-mounted instruments. Moreover, the adjacent Greenland shelf which is mostly ice-covered contributes to the dense water overflow to some extent [Girton, 2001].

[6] Here, results of an array of Acoustic Doppler Current Profilers (ADCP) and Pressure sensors/Inverted Echo Sounders (PIES) deployed on a section across the Denmark Strait sill from 1999 to 2003 are shown. The observations reveal changes of the overflow transport on interannual timescales that have not been measured before. Both compared to previous estimates and during our observation period, the overflow transport varied by $30 \%$.

\section{Methods}

[7] For the measurements presented here the long-term observing strategy has been optimized for the known spatial distribution of the overflow at the sill. This knowledge was based on various ship-occupied sections [Girton, 2001] and a numerical model experiment [Käse and Oschlies, 2000], which had proven to realistically reproduce the dense overflow [Käse et al., 2003]. A single observation point at the deepest part of the strait was not sufficient due to lateral variability and eddies. Therefore, measurements with 2-4 ADCPs across the channel were simulated and opti- 

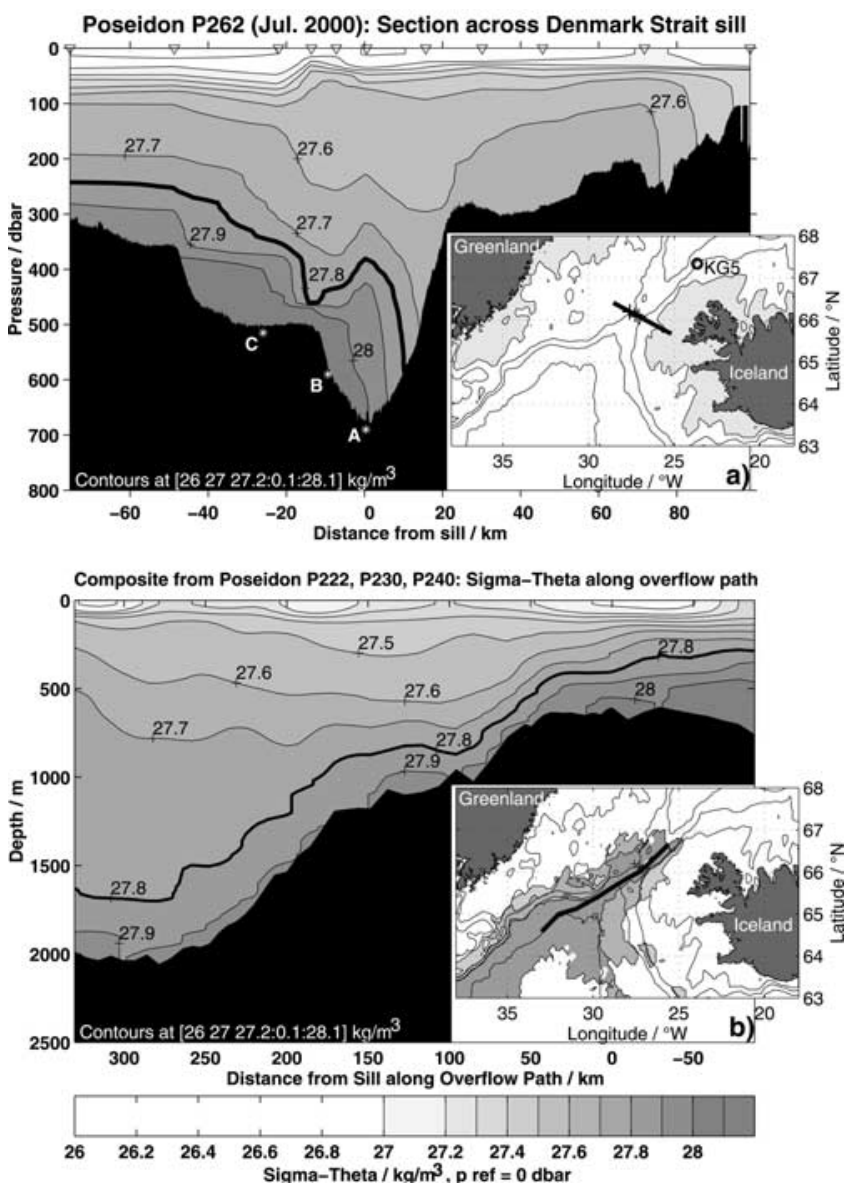

Figure 1. Potential density $\sigma_{\Theta}$ (density $-1000 \mathrm{~kg} \mathrm{~m}^{-3}$ ) sections of the Denmark Strait. In both panels, the 27.8 isopycnal is marked by a heavy line. (a) Cross section at the sill from a cruise of R/V Poseidon in 2000, showing the plume of dense water overflowing from the Nordic Seas. A, B, C mark positions of moored ADCPs. Inset map: Section location indicated as heavy line. KG5 denotes the repeated hydrographic station Kögur 5. 200, 500, 1000 and 2000 m isobaths contoured. (b) Section along the overflow path. The figure is a composite of three cruises of R/V Poseidon covering different regions of the overflow pathway. Note the decreasing density of the overflow plume due to mixing and entrainment on its downstream descent. Inset map: Heavy line shows location of the section. Bottom density contoured to indicate spatial coverage of the hydrographic surveys. Contour intervals indicated by the colorbar are valid for both panels.

mized with the numerical model. For any given number of instruments, a multilinear regression was applied to minimize the difference between the actual transport and the simulated ADCP observations in the model. Thus, optimum deployment locations and weights for constructing the transport integral for each ADCP were obtained to capture the overflow transport fluctuations with maximum correlation. Further, the regression yielded mean estimates for the average flow outside of the mooring array. The design chosen was an array of 3 bottom-mounted ADCPs (see Figure 1a for mooring positions). This increased the correlation between observed and true transport variability in the model from 0.5 (single instrument) to 0.87 . Due to technical problems, the actual time series available now only contains data from two locations for much of the time, which still yields an expected correlation of 0.8 . For a mean transport of $2.9 \mathrm{~Sv}$ in the model, the unresolved flow outside of the array (i.e. over the Greenland shelf), which was also determined in the simulation, proved to be $0.36 \mathrm{~Sv}(0.49 \mathrm{~Sv})$ for two ADCPs at positions A/B (B/C) (see Figure 1a) and $0.13 \mathrm{~Sv}$ for the optimum configuration of three ADCPs, respectively. In the field experiment, this was applied both as a fixed additive and as a multiplicative correction proportional to the observed transports. The differences between both correction methods are small enough $(<0.1 \mathrm{~Sv})$ to not change the main conclusions of this study.

[8] A critical factor is to detect the thickness of the dense water plume from bottom-mounted instruments. Three different methods were compared, determining the interface depth from the location of maximum current shear, from an acoustic backscatter maximum layer, and from a two layer sound propagation model using bottom pressure and acoustic travel time to the surface from PIES. All estimates agreed within $\pm 10 \%$ and do not give significantly different transport estimates. For the time series shown here, the depth of maximum current shear has been chosen as a kinematic definition of the upper boundary of the overflow plume.

\section{Results}

[9] The resulting total transport time series from 1999 until 2003 is shown in Figure 2a. The average transports for the four deployment periods are 3.68 and $3.66 \mathrm{~Sv}$ for 1999 2001, 3.16 Sv in 2001/2002, 3.07 Sv in 2002/2003. The curve shows significant interannual variability, with an overall $20 \%$ decrease of the transports. All deploymentmean transports are clearly larger than the previous estimates of 2.9 Sv [Ross, 1984; Girton, 2001], though on monthly timescales periods with smaller transports exist. Based on 40-hour low-passed time series, which retains the large variability on timescales of 2-10 days (not shown) [Ross, 1984; Girton, 2001], transports less than $2.9 \mathrm{~Sv}$ occurred during $34 \%$ of the total observation time 1999-2003. Several estimates from ship sections which showed values close to $2.9 \mathrm{~Sv}$ overlap with our mooring time series. These reveal that the ship sections were indeed measured during periods with smaller than average currents. We thus have evidence, that interannual changes in the overflow transport about $30 \%$ compared to previous estimates [Worthington, 1969; Aagaard and Malmberg, 1978; Ross, 1984; Girton, 2001] and also during our observation period have occurred.

[10] The temperature of the dense overflow (Figure 2b), also observed by the bottom-mounted ADCPs, shows interannual variability as well. We measured a significant warming by $0.5^{\circ} \mathrm{C}$ from 1999 to 2002 , which coincides with the transport decrease. After 2002, temperatures almost return to the values observed in 1999 .

[11] It is tempting to relate these changes to hydraulic control effects. According to theoretical studies [Whitehead, 1998] the maximum transport is given by $Q_{\max }=\frac{1}{2} \frac{g}{f} \frac{\Delta \mathrm{Q}}{\mathrm{Q}} H^{2}$ where $g$ is the acceleration of gravity, $f$ Coriolis parameter, $\varrho$ the density of the reservoir, $\Delta \mathrm{Q}$ its density contrast to the upper layer and $H$ the upstream reservoir height above the sill. Since this relation assumes highly idealized conditions 
(zero PV, rectangular channel), smaller transports are expected for more realistic cases [Käse et al., 2003; Nikolopoulos et al., 2003; Stern, 2004]. In any case of a hydraulically controlled flow, transport variations depend on reservoir height or density changes.

[12] Repeated hydrographic stations upstream of the sill suggest that the reservoir height has indeed decreased during the observation period. At the station Kögur 5 (KG5 in Figure 1a), which lies close to a major upstream pathway to the sill [Jónsson and Valdimarsson, 2004], the height of the $\sigma_{\Theta}=27.8 \mathrm{~kg} \mathrm{~m}^{-3}$ isopycnal $\left(\sigma_{\Theta}=\right.$ potential density $1000 \mathrm{~kg} \mathrm{~m}^{-3}$; commonly used as upper overflow bound [Girton, 2001]) above the $600 \mathrm{~m}$ deep sill varied between 500 and $400 \mathrm{~m}$, with a pronounced interannual decrease from Feb. 2001 to Nov. 2002. The resulting hydraulic transport estimates, in particular the annual averages, are almost identical to the direct observations at the sill (Figure 3a). It is notable that the hydraulic relation yields no overestimate of the actual transport, as would be expected from Whitehead [1998]; however, KG5, which lies on the Iceland side of the jet [Jónsson and Valdimarsson, 2004], might underestimate the actual reservoir height. Moreover, numerical models suggest that parts of the Denmark Strait overflow may be related to barotropic forcing [Biastoch et al., 2003].

[13] To test the density effect, the local correlation between temperature and transport at the sill was examined (Figure 3b). Neglecting upstream reservoir height changes, one would expect a linear correlation due to the $\Delta \mathrm{Q} / \mathrm{Q}$ term in the hydraulic relation. Assuming a density-temperature relation of $0.08 \mathrm{~kg} \mathrm{~m}^{-3}{ }^{\circ} \mathrm{C}^{-1}$ [Girton, 2001], and a fixed reservoir height of $500 \mathrm{~m}$, a transport change of $-0.73 \mathrm{~Sv}$ ${ }^{\circ} \mathrm{C}^{-1}$ would result from the hydraulic relation. This agrees with the regression slope of $-0.77 \pm 0.13 \mathrm{~Sv}{ }^{\circ} \mathrm{C}^{-1}$ that has been obtained from the actual time series (Figure 3b). Thus, both the observed reservoir height decrease and the local density-transport correlation are consistent with the measured transport changes. The data are not sufficient yet to prove either of the mechanisms.

[14] The warming observed at the sill (Figure 2b) is not evident at KG5 even though it lies close to a major pathway to the sill. [Jónsson and Valdimarsson, 2004] suggested, that the overflow entrains some warm Atlantic Water (AW) on its way from KG5 to the sill. The overflow warming at the sill might therefore point at enhanced entrainment of warm AW due to enhanced Atlantic inflow on the Iceland side.

[15] An additional mechanism explored in numerical experiments suggests that positive anomalies of the North Atlantic Oscillation (NAO) [Marshall et al., 2001] amplify the barotropic gyre circulation around Iceland and possibly also the dense overflow [Biastoch et al., 2003]. During the observation period, the NAO winter index decreased from a positive phase in 1999/2000 to negative values in 2003/ 2004 (National Centers for Environmental Prediction, Climate Prediction Center, http://www.cpc.ncep.noaa.gov/data/ teledoc/nao.html, 2002, data updated 2004), which would also reduce the dense overflow transport which we have detected.

\section{Conclusions}

[16] For the first time, interannual fluctuations of the Denmark Strait overflow have been observed. From 1999
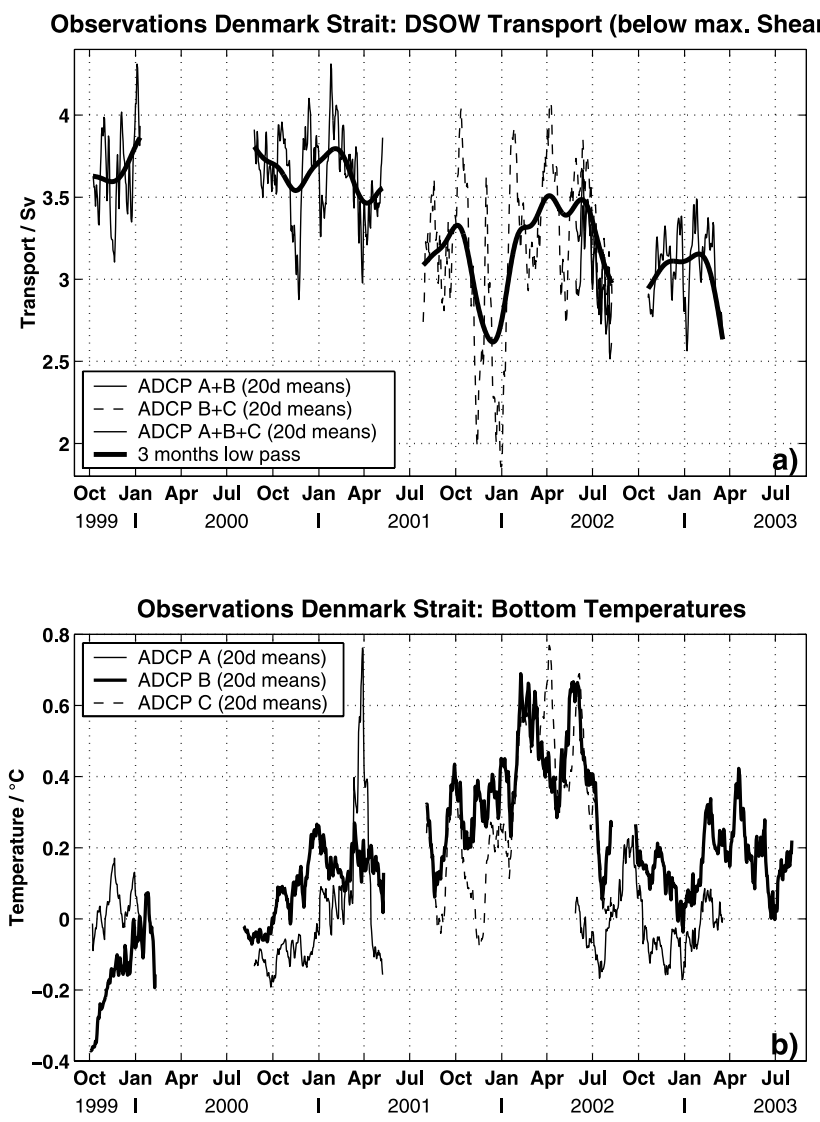

Figure 2. Total time series of observations at the sill. (a) Transport in $\mathrm{Sv}\left(1 \mathrm{~Sv}=10^{6} \mathrm{~m}^{3} \mathrm{~s}^{-1}\right)$ of the overflow below the layer of maximum current shear determined from at least two ADCPs operating at the same time (see legend). Thin lines show the 20-day low-pass filtered values, while the heavy line is a 3-month low-pass. The errors due to the imperfect sampling of the spatial variability (with correlation 0.8 ) are $0.1-0.2 \mathrm{~Sv}$ for the averages over the 4-12 month long deployment periods (assuming 25-70 degrees of freedom resulting from the observed [Ross, 1984; Girton, 2001] and modeled [Käse et al., 2003] eddy timescale of 5 days). All values are corrected for the systematic underestimate as derived from model data and verified by ship-sections. These corrections are expected to have an uncertainty of $\pm 0.2 \mathrm{~Sv}$ based on the differences obtained between different ADCP configurations and from ship section estimates. The time series from a 3-month period in summer 2002, where three ADCPs were available (smaller systematic underestimate, higher correlation) agrees with transports calculated from subsets of just two instruments $(\mathrm{A} / \mathrm{B}$, or $\mathrm{B} / \mathrm{C}$, respectively) within $\pm 0.2 \mathrm{~Sv}$ in the mean. This confirms that the correction yields realistic estimates. (b) Temperature of the dense overflow water, observed by the bottom-mounted ADCPs. The significant interannual temperature variability is best observed by ADCP B (heavy line), the only instrument that was operating during the entire experiment.

to 2003 , the volume transport, previously regarded to be stable at 2.7-2.9 Sv on interannual timescales, decreased from $3.68 \mathrm{~Sv}$ to $3.07 \mathrm{~Sv}$. The temperature of the overflow increased temporarily by $0.5^{\circ} \mathrm{C}$. There is evidence from the 


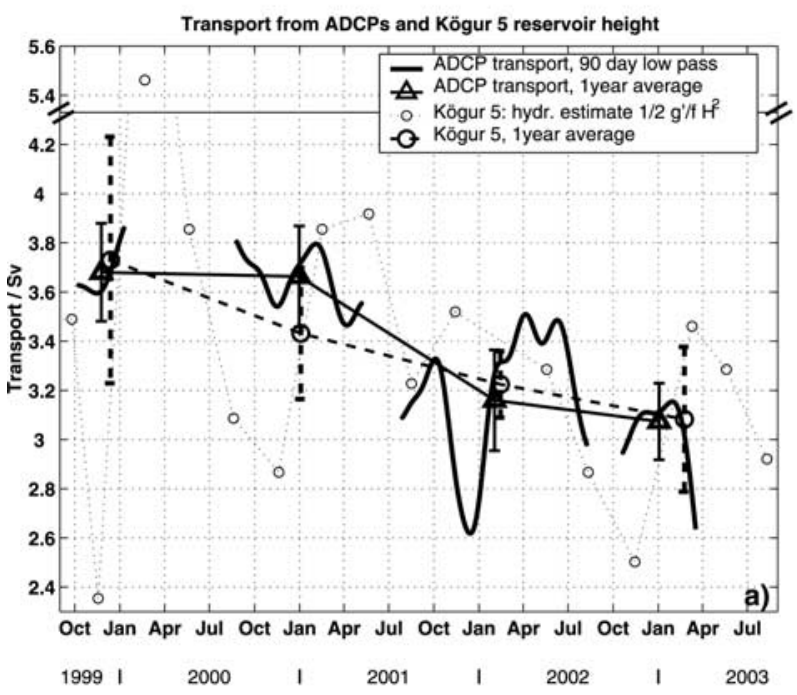

Denmark Strait Observations: Temperature (ADCP B)/Transport Relation

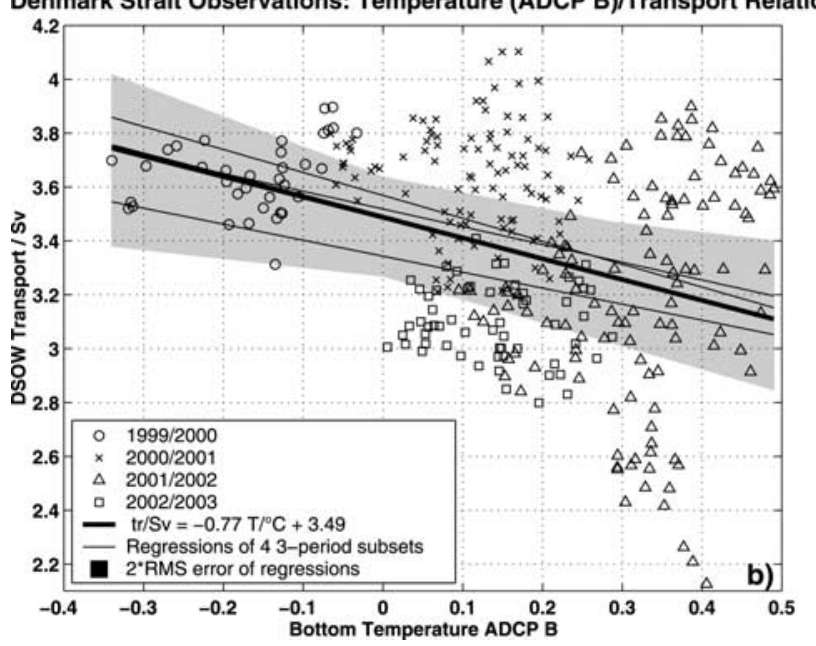

Figure 3. Tests of hydraulic estimates. (a) ADCP transport time series as in Figure $2 \mathrm{a}$ (solid lines) and transport, inferred from hydraulic relation [Whitehead, 1998] with $\Delta \mathrm{o}=0.43 \mathrm{~kg}$ $\mathrm{m}^{-3}$ [Girton, 2001] applied to the height of the 27.8 isopycnal at KG5 station above the sill (circles). For position of KG5, see Figure 1a. Heavy triangles and circles for ADCP and $\mathrm{KG5}$, respectively, denote yearly averages for each deployment period. Error bars show RMS errors of each yearly mean. The observed transports are almost equal to those calculated by the hydraulic relation. (b) Relation of bottom water temperature at ADCP B and the observed overflow transport, 30 days running means. The total regression line (heavy line) gives a slope of $-0.77 \pm$ $0.13 \mathrm{~Sv}{ }^{\circ} \mathrm{C}^{-1}$. Light lines denote linear regression of four different subsets with one deployment period omitted in each subset. One line is identical with the total regression within $\pm 0.01 \mathrm{~Sv}$. Shading indicates area smaller than twice the RMS error. The correlation of 0.35 is significant at the $95 \%$ confidence level, assuming 50 degrees of freedom for the whole time series. From hydraulic theory, a regression slope of $-0.73 \mathrm{~Sv}{ }^{\circ} \mathrm{C}^{-1}$ would be expected for constant reservoir height (see text). Although the mean regression is essentially similar within the error bounds, the low transport values in $2001 / 2002$ (triangles at $0.4{ }^{\circ} \mathrm{C} / 2.2 \mathrm{~Sv}$ ) cannot be accounted for by the temperature-density relation alone and require a reduced reservoir height, as shown in Figure 3a. observations, that hydraulic control mechanisms can be applied to the Denmark Strait overflow.

[17] The changes in the overflow documented here highlight the need to establish a long-term observing system for the transport of dense water between Greenland and Iceland, and also between Iceland and Scotland. The latter pathway may either be in phase with Denmark Strait (e.g. if hydraulics apply and if fed from the same reservoir) or may have a compensating effect as suggested in some studies [Biastoch et al., 2003]. Of major interest are the effects of such changes in the increased downstream transport due to entrainment and thus in the overall southward transport of the global overturning circulation which therefore needs to be observed in concert.

[18] Acknowledgment. This work was supported by the Deutsche Forschungsgemeinschaft in the Sonderforschungsbereich 460 project.

\section{References}

Aagaard, K., and S.-A. Malmberg (1978), Low frequency characteristics of the Denmark Strait overflow, ICES, CM 1978/C:47, Int. Counc. for the Explor. of the Sea, Copenhagen.

Biastoch, A., R. H. Käse, and D. B. Stammer (2003), The sensitivity of the Greenland-Scotland overflow to forcing changes, J. Phys. Oceanogr., 33, 2307-2319.

Dickson, R. R., and J. Brown (1994), The production of North Atlantic Deep Water: Sources, rates and pathways, J. Geophys. Res., 99, 12,31912,341 .

Girton, J. B. (2001), Dynamics of transport and variability in the Denmark Strait overflow, Ph.D. thesis, Univ. of Wash., Seattle.

Hansen, B., and S. Østerhus (2000), North Atlantic-Nordic Seas exchanges, Prog. Oceanogr. 45, 109-208.

Jónsson, S., and H. Valdimarsson (2004), A new path for the Denmark Strait Overflow Water from the Iceland Sea to Denmark Strait, Geophys. Res. Lett., 31, L03305, doi:10.1029/2003GL019214.

Käse, R. H., and A. Oschlies (2000), Flow through Denmark Strait, J. Geophys. Res., 105, 28,527-28,546.

Käse, R. H., J. B. Girton, and T. B. Sanford (2003), Structure and variability of the Denmark Strait Overflow: Model and observations, J. Geophys. Res., 108(C6), 3181, doi:10.1029/2002JC001548.

Marshall, J., Y. Kushnir, D. Battisti, P. Chang, A. Czaja, R. Dickson, M. McCartney, R. Saravanan, and M. Visbeck (2001), North Atlantic climate variability: Phenomena, impacts and mechanisms, Int. J. Climatol., 21, 1863-1898.

Nikolopoulos, A., K. Borenäs, R. Hietala, and P. Lundberg (2003), Hydraulic estimates of Denmark Strait overflow, J. Geophys. Res., 108(C3), 3095, doi:10.1029/2001JC001283.

Ross, C. K. (1984), Temperature-salinity characteristics of the "overflow" water in Denmark Strait during "Overflow'73", Rapp. P. V. Reun. Cons. Int. Explor. Mer., 185, 111-119.

Saunders, P. M. (2001), Ocean Circulation and Climate, Int. Geophys. Ser, vol. 77, pp. 401-418, Elsevier, New York.

Stern, M. E. (2004), Transport extremum through Denmark Strait, Geophys. Res. Lett., 31, L12303, doi:10.1029/2004GL020184.

Talley, L. D. (1996), North Atlantic circulation, reviewed for the CNLS conference, Physica D, 98, 625-646.

Whitehead, J. A. (1998), Topographic control of oceanic flows in deep passages and straits, Rev. Geophys., 36, 423-440.

Worthington, L. V. (1969), An attempt to measure the volume transport of Norwegian Sea overflow water through the Denmark Strait, Deep Sea Res., 16, 421-432.

S. Jónsson, Department of Natural Resource Sciences, University of Akureyri, Glerárgata 36, 600 Akureyri, Iceland. (steing@unak.is)

R. H. Käse, Zentrum für Meeres- und Klimaforschung, Institut für Meereskunde, Universität Hamburg, Bundesstraße 53, D-20146 Hamburg, Germany. (kaese@ifm.uni-hamburg.de)

A. Macrander and U. Send, Leibniz-Institut für Meereswissenschaften, IFM-GEOMAR, Düsternbrooker Weg 20, D-24105 Kiel, Germany. (amacrander@ifm-geomar.de)

H. Valdimarsson, Marine Research Institute, Skúlagata 4, 101 Reykjavík, Iceland. (hv@hafro.is) 